\title{
TRANSFORMASI PEMBELAJARAN ILMU FALAK DI ERA INDUSTRI 4.0 (APPLICATION AND INSPIRING LEARNING METHODS)
}

\author{
Mursyid Fikri ${ }^{1}$, \\ Universitas Muhammadiyah Makassar, Jl. Sultan Alauddin, Makassar, 90221, Indonesia \\ mursyidfikri4@gmail.com, \\ Baharuddin 2, \\ Universitas Islam “45”Bekasi,Indonesia \\ afinyeyen@yahoo.com
}

\begin{abstract}
Abstrak
Industri telah mengalami Fase revolusi yang begitu pesat yakni industri 4.0 hal ini membawa konsekuensi terhadap pendidikan sains dan syariah untuk mampu mempersiapkan individu yang memiliki kompetensi dalam mengahadapi berbagai tantangan dimasa depan dengan mengaplikasikan atau menghasilkan sebuah karya yang menjadi simbol dialektika keilmuan. Penelitian ini merupakan library reaserch dengan menggunakan pendekatan metode kualitatif deskriptif yang menghubungkan antara teori yang ada dengan realitas deskriptif ilmu falak saat ini. Ilmu falak merupakan bagian yang terpenting dalam sejarah peradaban Islam. Sejarah telah mencatat, cendekiawan dan para Al-Falaky (gelar bagi pegiat falak) bermunculan saat peradaban Islam di puncak keemasan dan ketika Islam mengalami kemunduran gaung ilmu falak tidak lagi didengar bahkan umat Islam pun saat ini banyak yang tidak mengenal istilah "Ilmu falak". Fenomena tersebut menandakan bahwa adanya korelasi positif antara tegaknya peradaban Islam dengan perkembangan Islam yang menjadi simbol keilmuan falak yang merupakan cerminan eksistensi Islam. Oleh sebab itu diperlukan adanya transformasi/revolusi gerakan pembelajaran ilmu falak yang bukan hanya berputar pada taraf teoritris semata melainkan application and inspiring learning mehtods dengan memafaatkan perkembangan media industri 4.0 untuk memperkenalkan ilmu falak serta mengokohkan pembelajaran ilmu falak. Transformasi keilmuan tersebut setidaknya mampu menyentuh tiga dimensi keilmuan yakni dimensi intelektualitas, dimensi spritualitas dan dimensi sosial politik.
\end{abstract}

Kata kunci: Transformasi, Pembelajaran Ilmu Falak, Industri 4.0.

\begin{abstract}
The industry has experienced a very rapid revolution phase, namely industry 4.0, this has consequences for science and sharia education to be able to prepare individuals who have competence in facing various challenges in the future by applying or producing a work that is a symbol of scientific dialectics. This research is a library research using a descriptive qualitative method approach that connects the existing
\end{abstract}


theory with the descriptive reality of astronomy today. Astrology is the most important part in the history of Islamic civilization. History has recorded, scholars and Al-Falaky (a title for astronomy activists) emerged when Islamic civilization was at its golden peak and when Islam experienced a decline the echo of astronomy was no longer heard, even today many Muslims are not familiar with the term "science of astronomy". This phenomenon indicates that there is a positive correlation between the establishment of Islamic civilization and the development of Islam which is a symbol of astronomy science which is a reflection of the existence of Islam. Therefore, there is a need for a transformation/revolution of the astronomy learning movement which does not only revolve at the theoretical level, but also application and inspiring learning methods by utilizing the development of industrial media 4.0 to introduce astronomy and strengthen astronomy learning. The scientific transformation is at least able to touch three scientific dimensions, namely the intellectual dimension, the spiritual dimension and the socio-political dimension.

$\vartheta$

Keywords: Transformation, Astronomy Learning, Industry 4.0. 


\section{PENDAHULUAN}

Pada abad 21 ini, dunia pendidikan dan pembelajaran di Indonesia menghadapi tiga tantangan besar; Pertama, sebagai akibat dari krisis global yang melanda dunia termasuk juga dengan Indonesia sebagai bagian dari negara ke tiga yang berkembang. Demikian juga dengan dunia pendidikan mengalami perubahan untuk menyesuaikan diri dengan perkembangan masyarakat dunia. Kedua, dampak dari perkembangan global tadi dibutuhkan antisipasi yang serius, dunia pendidikan dituntut untuk mempersiapkan sumber daya manusia yang mampu bersaing dengan keadaan perubahan jaman mengikuti era globalisasi. Ketiga, sejalan dengan tuntutan perkembangan jaman, dilakukan otonomi daerah, dengan maksud agar sumber-sumber daya yang dimiliki di suatu daerah dapat dikembangkan secara maksimal untuk kepentingan bersama, perlu dilakukan perubahan dan penyesuaian arah pendidikan nasional sehingga dapat mewujudkan proses pendidikan yang demokratis, memperhatikan keragaman kebutuhan dan keadaan daerah termasuk peserta didik dan pada akhirnya pendidikan mampu mendorong partisipasi masyarakat (Ansori \& Samsudin, 2013).

Awal perkembangan pendidikan sains di dunia Islam tidak bisa dilepaskan dari sejarah ekspansi Islam itu sendiri. Dalam kurun waktu lebih kurang dua puluh lima tahun setelah wafatnya Nabi Muhammad SAW, pada tahun 632 M, kaum Muslim telah berhasil menaklukkan seluruh Jazirah Arabia dari selatan hingga utara. Ekspansi dakwah yang dalam sejarah Islam disebut sebagai pembukaan negeri-negeri (futuh al buldan) ini berlangsung pesat dan tak terbendung. Sejarah telah mencatat, bahwa diantara bangsa-bangsa yang kontribusinya kepada perkembangan ilmu pengetahuan tidak bisa diabaikan begitu saja, yaitu masyarakat Muslim dengan peradaban Islamnya. Begitu pentingnya sumbangan mereka sehingga seseorang bisa berkata dengan yakin bahwa jika orang Muslim tidak melakukan apa yang telah mereka kerjakan dalam berbagai lapangan sains, niscaya revolusi ilmu pengetahuan di Eropa Barat tidak akan pernah tumbuh dan berkembang pada saat itu. Seseorang juga bisa berargumentasi logis bahwa revolusi ilmu pengetahuan akan dapat terjadi di dunia Muslim jika saja tidak terjadi peristiwa-peristiwa yang mengakibatkan berhentinya perkembangan sains pada saat itu (Hasyim, 2012).

Anggapan umum bahwa kemajuan sains dan teknologi di dunia Barat (Eropa dan Amerika) sejak beberapa abad sampai dekade terakhir ini disebabkan antara lain dan terutama sekali adalah oleh faham sekularisasi yang mengakhiri dengan apa yang disebut sebagai zaman kegelapan, dan asumsi ini memang ada benarnya mengingat hubungan yang tidak harmonis sepanjang sejarah antara dogmatis Gereja dan rasionalisme para saintis. Konflik berkepanjangan inilah 
akhirnya menjadi semakin sengit dan bahkan satu dengan yang lain berusaha menjatuhkan dan tidak segan-segan menindasnya.

Prioritas utama pendidikan keagamaan, terutama pendidikan Islam, adalah terbentuknya manusia yang beriman, cerdas, kreatif, dan memiliki keluhuran budi pekerti. Untuk mengantarkan manusia pada cita-cita tersebut, misi pendidikan Islam harus mengarahkan kehidupan dan keberagamaan manusia ke arah kehidupan Islami yang ideal(Samsuddin, 2012).

Dalam hal ini segala bentuk pengajaran dan pembinaan pendidikan Islam begitu pula pengajaran ilmu falak harus bermuara pada peningkatan kualitas keimanan peserta didik, Jika upaya pendidikan mengalami kegagalan dalam mengantarkan manusia ke arah cita-cita manusiawi yang bersandar pada nilai-nilai ketuhanan, maka yang akan terjadi adalah tumbuhnya perilaku-perilaku negatif dan destruktif, seperti kekerasan, radikalisme, fundamentalisme, terorisme, dan ketidakpedulian sosial, yang semuanya itu berimplikasi pada penderitaan semesta (Munir, 1993).

Ilmu falak sendiri merupakan bagian yang terpenting dalam sejarah peradaban dan pembelajaran Islam. Sejarah telah mencatat, cendekiawan dan para Al-Falaky (gelar bagi pegiat falak) bermunculan saat perdaban Islam di puncak keemasan dan ketika Islam mengalami kemunduran gaung ilmu falak tidak lagi didengar bahkan umat Islampun saat ini banyak yang tidak mengenal istilah "Ilmu falak". Fenomena tersebut menandakan bahwa adanya korelasi positif antara tegaknya peradaban Islam dengan perkembangan Islam yang menjadi simbol keilmuan falak yang merupakan cerminan eksistensi Islam.

Era 4.0 kita kenal sebagai era revolusi industri, di mana segala segi kehidupan didominasi oleh pemanfaatan teknologi digital guna mempermudah aktivitas sehari-hari, terutama dalam aspek pendidikan melalui metode pembelajarannya. Teknologi digital, khususnya teknologi informasi (IT), dapat dimanfaatkan sebagai strategi jitu dalam meningkatkan kualitas serta keunggulan perguruan tinggi, yang mencakup kurikulum,

fasilitas, pelayanan, serta sistem pembelajaran yang secara keseluruhan telah menggunakan teknologi digital.

Dalam konteks inilah, pendidikan Islam dalam hal ini pembelajaran Ilmu falak yang seharusnya menjadi salah satu media penyadaran umat dihadapkan pada problem bagaimana mengembangkan pola pendidikan transformatif; sebuah pola yang mampu memberikan pemahaman dan transformasi pembelajaran yang tidak saja bertumpu pada transfer pengetahuan semata, tetapi juga transfer nilai pengetahuan. Pendidikan transformatif juga menghasilkan pola pembelajaran yang tidak hanya berpusat pada pendidik (teacher centered), tetapi lebih pada pola 
pembelajaran yang memberikan "ruang" bagi peserta didik untuk lebih mengaktualisasikan potensi akademisnya secara maksimal dengan mendekatan metode yang bersipat aplikatif dan inspiratif

\section{METODE PENELITIAN}

Penelitian ini merupakan library reaserch dengan menggunakan pendekatan metode kualitatif deskriptif yang menghubungkan antara teori yang ada dengan realitas deskriptif ilmu falak saat ini. Sedangkan sumbernya diambil dari beberapa buku-buku ilmiah yang diterbitkan dengan maksud dijadikan sumber referensi Adapun Tekhnik pengumpulan data dalam penelitian ini ialah Studi Kepustakaan, Wawancara dan Observasi.

\section{PEMBAHASAN}

\section{Transformasi Pembelajaran Ilmu Falak}

Istilah transformasi dalam kamus besar bahasa indonesia diartikan sebagai perubahan struktur gramatikal menjadi struktur gramatikal lainnya dengan menambah, mengurangi atau menata kembali unsur-unsurnya (Nasional, 2003).Transformasi seringkali dihadirkan dalam wacanaposmodernisme sebagai antitesis modernisme. Posmodernisme sendiri diartikan oleh Anthony Giddens sebagai "sebuah estetika, sastra, politik atau filsafat sosial, yang merupakan dasar dari upaya untuk menggambarkan suatu kondisi yang berkaitan dengan perubahan pada lembaga-lembaga dan kondisi sebagai postmodenitas"(Sarup, 2003). Ini berarti posmodernisme merupakan kondisi budaya yang menjadi antitesis sehingga memunculkan banyak transformasi yang mengubah how to play and the rule of the game dalam bidang sains, sastra, dan seni. Di bidang pendidikan, transformasi berupa perubahan aturan main dalam hal aspek, praktik, metode pengajaran, institusi pendidikan yang bertanggung jawab dan mentransmisikan suatu ilmu pengetahuan. 
Suatu Pembelajaran dianggap berhasil jika mampu mencetak pribadi yang solutif terhadap persoalan lingkungan. Untuk menghasilkan pribadi yang semacam itu, berbagai elemen pembelajaran harus ditinjau ulang. Kurikulum harus lebih terkait dengan current issues sehingga dapat memberikan bekal pengetahuan dan pengalaman kepada peserta didik tentang problem riil di masyarakat. Apabila tidak sejalan dengan konsep ini, maka strategi pendidikan di Indonesia telah mengabaikan visi pendidikan 2030; sebuah visi yang berorientasi global dan berbasis kerakyatan(Raihani, 2010). Karena itu, evaluasi proses pembelajaran harus lebih berpijak pada potensi kemanusiaan peserta didik, bukan uniform yang dipaksakan oleh pendidik. Dalam hal pengelolaan, pengelola lembaga pendidikan harus mampu menggerakkan dan mengaktifkan setiap potensi yang ada di sekitarnya untuk ikut memikirkan persoalan pendidikan. Diskursus di atas menyatakan keharusan adanya pembaruan cara pandang terhadap proses pengajaran dan pembelajaran ilmu falak.

Dengan menggunakan kerangka semacam ini, bagaimana pola pengajaran ilmu Falak mampu melakukan transformasi dari praktik pendidikan yang telah ada menuju kondisi yang lebih baik, mulai dari aspek konseptualisasi hingga implementasi, dan peran seperti kelembagaan, kurikulum, strategi pembelajaran, dan penyediaan Sumber Daya Insani (SDI) yang berorientasi pada reaktualisasi peran dan fungsi ilmu falak dalam kehidupan masyarakat.

Sebagai ilmu yang bersifat sains dan praktis ilmu falak harus memiliki beberapa persyaratan yang menjadi ciri-ciri pengajarannya agar dapat memenuhi sasaran yang hendak di capai. Adapun ciri-ciri pokok tersebut dapat di kemukakan sebagai berikut :

Pertama Dalam hal tujuan, pembelajaran ilmu falak harus diorientasikan untuk mencetak individu yang berkesadaran kenabian, yang mempunyai misi liberatif terhadap berbagai persoalan terkait peribadatan umat Islam. Strategi pembelajaran harus diorientasikan untuk mengoptimalkan setiap potensi yang dimiliki oleh peserta didik dengan orientasi produktif skill.

Kedua Proses pengajaran Yang Menarik; Menarik dalam arti ditinjau dari segi pelaksanaan dan hasil tentu harus menarik bagi peserta didik. Dengan cara-cara pelaksanaan yang menarik, akan memperlancar peserta mengikuti pendidikan yang diberikan seperti pengadaan fasilitas tempat belajar, bahan-bahan untuk praktek penyesuaian waktu belajar dan lainnya. Dari segi hasil yang baik berarti apa yang dicapai benar-benar bermanfaat bagi 
keseluruhan peserta didik sekaligus bermanfaat untuk masyarakat. Keberhasilan konsep percontohan (pilot project) dapat membangkitkan minat peserta untuk mempraktekkan dan mengembangkan proses pembelajaran dalam hal ini ilmu yang didapatkannya secara mandiri. Dunia pendidikan saat ini juga dituntut mampu membekali para peserta didik dengan keterampilan abad 21. Keterampilan ini adalah keterampilan peserta didik yang mampu untuk berfikir kritis dan memecahkan masalah, kreatif dan inovatif, ketrampilan berkomunikasi dan kolaborasi. Selain itu keterampilan mencari, mengelola dan menyampaikan informasi serta terampil menggunakan teknologi dan informasi. Kemampuan yang harus dimiliki di abad 21 ini meliputi: Leadership, Digital Literacy, Communication, Emotional Intelligence, Entrepreneurship, Global Citizenship, Problem Solving, Team-working. Sedangkan tiga isu pendidikan di Indonesia saat ini adalah Pendidikan karakter, pendidikan vokas dan inovasi (Wibawa, 2018).

Ketiga memiliki output public oriented dalam artian segala proses pengajaran ilmu falak harus bermanfaat terhadap masyarakat khususnya dalam hal peribadatan umat Islam. Pengajaran ilmu falak seharusnya tidak sekedar membentuk kesalehan individual semata, atau kesadaran mistik dalam perspektif Muhammad Iqbal, namun harus membentuk kesalehan sosial juga. Sebagaimana disinyalir Iqbal pada awal abad ke-20 dan hingga sekarang masih terasa, umat Islam di dunia Timur cenderung mengedepankan kesadaran mistik dan kesalehan individual yang diibaratkan dengan larut dengan tasbih, yang penting selamat di akhirat, sementara problem sekitar tidak begitu dipikirkan (Saiyidain, 1981). Untuk itu, menurut Azyumardi Azra orientasi pendidikan harus diarahkan untuk dapat menjawab kebutuhan dan tantangan yang muncul dalam masyarakat sebagai konsekuensi dari perubahan(Azra, 1999). Akhirnya membentuk individu Muslim yang mempunyai kesadaran profetik dengan karakter emansipatif, liberatif dan transendental yang mampu membaca problem empirik di sekitarnya sehingga ia mampu terlibat dalam penyelesaian problem. Tetapi, di sisi lain, dia juga mampu menyelesaikan setiap problem yang menimpanya.

Olehnya itu di harapkan pembelajaran ilmu falak harus mampu menjawab segala bentuk keresahan public terhadap sesuatu hal yang berkaitan dengan ketuhanan yang berdampak terhadap problem empirik peribadatan umat Islam. 
Keempat pembelajaran berbasis proyek. Peserta didik saat ini harus sudah dapat beradaptasi dengan pembelajaran berbasis proyek, demikian juga dalam hal bekerja. Ini menunjukkan bahwa mereka harus belajar bagaimana menerapkan keterampilan mereka dalam jangka pendek ke berbagai situasi. Mereka sudah harus berkenalan dengan pembelajaran berbasis proyek dalam bentuk keterampilan mengorganisasi, kolaborasi, dan manajemen waktu diajarkan kepada peserta didik untuk kemudian dapat digunakan dalam rangka mengoptimalkan kemampuannya untuk menciptakan media pembelajaran sendiri.

\section{Dimensi Pembelajar Ilmu Falak Di Era Industri 4.0}

Konsep revolusi industri 4.0 ini merupakan konsep yang pertama kali diperkenalkan oleh Profesor Klaus Schwab. Beliau merupakan ekonom terkenal asal Jerman sekaligus penggagas World Economic Forum (WEF) yang melalui bukunya, The Fourth Industrial Revolution, menyatakan bahwa revolusi industri 4.0 secara fundamental dapat mengubah cara kita hidup, bekerja, dan berhubungan satu dengan yang lain . ${ }^{12}$

Richard Mengko, yang mengutip dari A.T. Kearney dalam Stevani Halim. ${ }^{13}$ menggambarkan empat tahap evolusi industri. Pertama, Revolusi industri yang pertama terjadi pada akhir abad ke-18. Hal ini ditandai dengan ditemukannya alat tenun mekanis pertama pada tahun 1784. Kedua, Revolusi industri 2.0 terjadi di awal abad ke-20. Kala itu ada pengenalan produksi massal berdasarkan pembagian kerja. Ketiga, Awal tahun 1970 ditengarai sebagai perdana kemunculan revolusi industri 3.0 yang dimulai dengan penggunaan elektronik dan teknologi informasi guna otomatisasi produksi. Terakhir, 2018 hingga sekaranglah zaman revolusi industri 4.0. Industri 4.0 adalah industri yang menggabungkan teknologi otomatisasi dengan teknologi cyber. Ini merupakan tren otomatisasi dan pertukaran data dalam teknologi manufaktur. Pada era ini, industri mulai menyentuh dunia virtual, berbentuk konektivitas manusia, mesin dan data, semua sudah ada di mana-mana, atau mengenalnya dengan istilah Internet of Things (IoT). ${ }^{14}$

Industri 4.0 selanjutnya hadir menggantikan industri 3.0 yang ditandai dengan cyber fisik dan kolaborasi manufaktur. 121314 Lee, Lapira, Bagheri, \& Kao menjelaskan, industri 4.0 ditandai dengan peningkatan digitalisasi manufaktur yang didorong oleh empat faktor: 1) peningkatan volume data, kekuatan komputasi, dan konektivitas; 2) munculnya analisis, kemampuan, dan kecerdasan bisnis; 3) terjadinya bentuk interaksi baru antara manusia dengan mesin; dan 4) perbaikan instruksi transfer digital ke dunia fisik, seperti robotika dan 3D printing. Prinsip dasar industri 4.0 adalah penggabungan mesin, alur kerja, dan sistem, dengan 
menerapkan jaringan cerdas di sepanjang rantai dan proses produksi untuk mengendalikan satu sama lain secara mandiri 15

Pertama, Ilmu Falak dalam dimensi intelektualitas berdasarkan lintasan sejarah kehadiranya merupakan buah dari semangat para ilmuan Islam terdahulu sebagai bentuk pengejawantahan Firman Allah Swt yang pertama kali turun (Al-Alaq 1-5) yang merupakan Implementasi dari semangat Keingintahuan dan usaha yang real dalam mengaplikasikan perintah membaca, mentadabburi dan meresapi sepenuh hati ciptaan Allah SWT.

Ini membuktikan bahwa Peradaban Islam muncul karena Adanya rasa patuh dan taat akan Perintah Allah SWT dalam terus mengembangkan Pengetahuan manusia baik pengetahuan tentang dirinya, orang lain terlebih lagi pengetahuan yang berhubungan dengan Alam semesta. Maka sepatutnya dimensi keilmuan tersebut harus mampu menumbuhkan sikap Tawadhu bagi seorang pegiat Falak bahwa manusia Hakikatnya sangat kecil ketika di bandingkan dengan Ciptaan Allah yang lainnya, terlebih lagi ketika mau di bandingkan dengan kebesaran Allah SWT.

Sehingga ketika dalam transformasi pembelajaran hal ini yang senantiasa ditumbuhkan maka hal tersebut berkorelasi Positif terhadap ghirah jihad Para penuntut ilmu untuk senantiasa mengembangkan, menumbuhkan dan menghidupkan semangat berkarya. Karena sangat di sayangkan buah dari perkembangan ilmu Falak hanya terbatas dalam ruang lingkup Kajian teoritis tanpa Menghasilkan sebua karya orisinil yang baru, berupa instrumen penunjang pembelajaran Ilmu falak yang nantinya menjadi simbol pergolakan budaya intelktualitas di dalam Dunia Islam.

Di era 4.0 ini pengembangan instrumen falak perlu diarahkan pada pengenalan robot digital program, dalam menghasilkan sebuah instrumen bukan lagi pada tatanan instrumen klasik melainkan sudah terarah pada smart instrumen dalam bentuk robot yang mampu mengedukasi, kalkulasi segala bentuk gerak solar sistem baik dalam menentukan arah kiblat, awal bulan maupun waktu shalat.

Kedua, Ditinjau dari dimensi Spritualitas, ilmu falak Merupakan bukti kecintaan para pegiatnya Akan peribadatan umat Islam, mengingat bahwa Kunci tegaknya Islam terletak 
pada sejauh mana kedisiplinan manusia dalam menjalankan perintah Allah SWT terkhusus menjalankan kewajiban perintah Sholat, Puasa dan hari raya besar Islam. Nabi Muhammad Saw bersabda "bahwa sholat adalah tiangnya agama, barang siapa yang meneggakan shalat maka telah meneggakkan agama" sehingga kehadiran ilmu falak merupakan cerminan tegaknya agama Islam.

Oleh sebab itu harusnya ilmu falak tidak hanya mencakup hitungan astronomis penentuan waktu-waktu shalat namun harus mengarah pada dimensi spritualitas yakni menegakkan kedisiplinan dan kesadaran shalat di awal waktu. Pada proses pembelajaran ilmu falak tidak bisa dipisakan dengan sisi dakwah yang berorientasi pada kedisiplinan waktu sehingga ini menjadi bekal bagi para pegiatnya untuk tumbuh menjadi insan yang mandiri dan profesional.

Ketiga, menjadi ruang lingkup dimensi ilmu falak yakni erat kaitannya terhadap dinamika sosial dan politik, suatu bangsa dapat dikenang dalam sejarah ketika memiliki peninggalan berupa simbol kejayaan kebangsaan dan kebudayaan, sama halnya dalam sejarah kekhalifaan Islam dalam pengebangan ilmu falak yang menjadi penanda kejayaan Islam di masa itu. Khalifah al-ma'mun mencatat sebagai khalifah pertama yang mendirikan observatorium dalam perdaban Islam yaitu observatorium yang berlokasi di dua pos observasi yakni Syamsiyah di baghdad dan di bukit Qasiyun damaskus.

Observatorium ini hadir karena adanya persentuhan antara dunia politik dan kebutuhan sosial masyarakat Islam khususnya ilmuan Islam di masa itu. Dan pengembangan observatorium berikutnya lahir dari buah persentuhan antara penguasa (raja) dan ilmuan falak oleh sebab itu peran penguasa dalam menciptakan sebuah simbol peradaban sangatlah signifikan. Olehnya itu untuk mengembaikkan kejayaan Ilmu falak peran pemerintah dalam menghasilkan proyek instrumen keilmuan yang dapat di nikmati oleh seluruh lapisan masyarakat sekaligus proyek tersebut menjadi simbol kejayaan suatu negara. Sangat di sayangkan hari ini perkemabngan observatorium di indonesia sangatlah lambat dikarenakan pengelolaan observatorium bersifat pribadi bahkan persebarannyapun tidak merata di suluruh indonesia. Sulawesi Selatan sendiri sampai saat belum memiliki observatorium yang dapat di jadikan pusat pemantauaan gerak benda-benda langit. 


\section{KESIMPULAN}

Pembelajaran ilmu falak perlu melakukan transformasi gerakan yang tidak hanya berputar pada taraf teoritris semata melainkan application and inspiring learning mehtods dengan memafaatkan perkembangan media industri 4.0 untuk memperkenalkan ilmu falak serta mengokohkan pembelajaran ilmu falak. Transformasi keilmuan tersebut setidaknya mampu menyentuh tiga dimensi keilmuan yakni dimensi intelektualitas, dimensi spritualitas dan dimensi sosial politik.

Para pegiat falak perlu melakukan peneropongan terhadap berbagai problematika keilmuan falak bukan hanya fokus terhadap meneropong benda-benda langit khususnya hilal awal bulan namun perlu merancang strategi pengajaran ilmu falak yang menyentuh berbagai lini pendidikan menengah atas dan pasantrenpasantren. Sehinggah girah keinginan mengembangkan peradaban Islam semakin tertanan di dalam jiwa para peserta didik. Gerakan komunitas falak berkemajuan merupakan ide yang di tawarkan untuk bergerak mengembangkan, mensosialisasikan dan mengajarkan berbagai aktivitas falak yang sarat akan nilai sejarah dan perjuangan.

\section{KEPUSTAKAAN}


Ansori, A., \& Samsudin, A. (2013). TRANSFORMASI PEMBELAJARAN DI PENDIDKAN NON FORMAL (Upaya mempersiapkan pendidik dan peserta didik dalam menghadapi tantangan global untuk menjadi manusia pembelajar). EMPOWERMENT: Jurnal Ilmiah Program Studi Pendidikan Luar Sekolah, 2(1), $1-15$.

Azra, A. (1999). Pendidikan Islam: Tradisi dan Modernisasi Menuju Milenium Baru (Jakarta. Logos.

Hasyim, F. (2012). ILmU PengetAHUAn dAn PeRkemBAngAnnYA: tantangan kemajuan dan kemunduran dunia muslim. ULUL ALBAB Jurnal Studi Islam, 13(1), 1-17.

Munir, A. M. (1993). Paradigma intelektual muslim. Pengantar Filsafat Pendidikan Islam.

Nasional, P. B. D. P. (2003). Kamus Besar Bahasa Indonesia Jakarta: Balai Pustaka.

Raihani, R. (2010). Kepemimpinan sekolah transformatif. LKiS Yogykarta.

Saiyidain, K. G. (1981). Percikan Filsafat Iqbal Mengenai Pendidikan, terj. MI Soelaeman, Bandung: Diponegoro.

Samsuddin, S. (2012). Format Baru Transformasi Pendidikan Islam. Islamica: Jurnal Studi Keislaman, 7(1), 161-185.

Sarup, M. (2003). Posstrukturalisme dan Posmodernisme: Sebuah Pengantar Kritis. Yogyakarta: Penerbit Jendela.

Wibawa, S. (2018). Pendidikan dalam era revolusi industri 4.0. Indonesia. Yogyakarta: UST Yogyakarta.

Halim, Stevani, 2018, "Revolusi Industri 4.0 Di Indonesia," Medium.Com, last modified, lihat situs https://medium.com/@stevanihalim/revolusi-industri4-0di-indonesia- c32ea95033da

Klaus Schwab, 2016, The Fourth Industrial Revolution: What It Means and How to Respond, World Economic Forum, , lihat situs https://www.weforum.org/agenda/2016/01/thefourth-industrial-revolutionwhat-it- means-and-how-torespond/.

Klaus Schwab, 2016, The Fourth Industrial Revolution: What It Means and How to Respond, World Economic Forum, , lihat situs https://www.weforum.org/agenda/2016/01/thefourth-industrial-revolutionwhat-it- means-and-how-torespond/. 